\title{
Pembelajaran Kooperatif Daring Tipe Gi Berbantuan Microsoft Teams terhadap Pemahaman Konsep
}

\author{
${ }^{1}$ Dewi Astuti, ${ }^{2}$ Cholis Sa'dijah, ${ }^{3}$ Susiswo \\ Prodi S2 Pendidikan Matematika Universitas Negeri Malang, \\ Jl. Semarang No.5, Sumbersari, Kec. Lowokwaru, Kota Malang, Jawa Timur \\ Indonesia
}

Email: ${ }^{1}$ dewiastutik.1903117@ @students.um.ac.id, ${ }^{2}$ cholis.sadijah.fmipa@um.ac.id, ${ }^{3}$ susiswo.fmipa@um.ac.id

\section{Tersedia Online di}

http://www.jurnal.unublitar.ac.id/ index.php/briliant

\section{Sejarah Artikel}

Diterima pada Februari 2021

Disetuji pada Mei 2021

Dipublikasikan pada Mei 2021

Hal. 309-320

\section{Kata Kunci:}

Kooperatif daring, group

investigation, Microsoft Teams, pemahaman konsep, matriks

\section{DOI:}

http://dx.doi.org/10.28926/briliant .v3i4.631

Abstrak: Pada pembelajaran saat ini diperlukan model pembelajaran daring yang dapat meningkatkan pemahaman konsep siswa. Oleh karena itu, tujuan penelitian ini adalah untuk mengetahui perbedaan pembelajaran kooperatif daring tipe Group Investigation (GI) berbantuan Microsoft Teams terhadap pemahaman konsep. Penelitian ini merupakan penelitian kuantitatif jenis quasi experimental design dengan pre-test dan posttest. Subjek penelitian adalah kelas XI IPS 2 dan XI IPS 3 MAN Kota yang mengikuti pembelajaran daring. Kelas XI IPS 2 sebagai kelas eksperimen dengan pembelajaran kooperatif daring tipe GI berbantuan Microsoft Teams sedangkan kelas XI IPS 3 sebagai kelas kontrol dengan pembelajaran konvensional. Hasil temuan penelitian ini adalah pemahaman konsep siswa setelah pembelajaran kooperatif daring tipe GI berbantuan Microsoft Teams meningkat, terdapat perbedaan kemampuan pemahaman konsep matriks siswa yang memperoleh pembelajaran kooperatif daring tipe GI berbantuan

Microsoft Teams dengan siswa yang memperoleh pembelajaran konvensional dan pemahaman konsep matriks siswa pada pembelajaran kooperatif daring tipe GI berbantuan Microsoft Teams lebih baik daripada siswa pada pembelajaran konvensional.

\section{PENDAHULUAN}

Pembelajaran saat ini lebih menekankan pada pembelajaran yang berpusat pada siswa (Kemendikbud, 2013). Dalam pembelajaran khususnya Matematika, siswa memiliki pilihan terhadap materi yang dipelajari, pola interaksi yang digunakan dan pola pembelajaran yang dilakukan disesuaikan dengan kebutuhan masing-masing siswa. Guru bertindak sebagai fasilitator bertugas untuk mengarahkan siswa menemukan dan mengembangkan berbagai fakta dalam kehidupan, membangun konsep serta mengembangkan nilai-nilai yang diperlukan untuk kehidupan.

Dengan memahami suatu konsep, memungkinkan siswa untuk menggunakan suatu ide dan menyesuaikan beberapa ide matematika yang dikuasai ke situasi-situasi yang baru sehingga belajar akan semakin bermakna (NCTM, 2000; Sukoriyanto dkk., 2016; Utami dkk., 2017). Menurut (Aledya, 2019; Ardianto \& Kuswandi, 2017), dengan pemahaman konsep siswa juga akan

309 BRILIANT: Jurnal Riset dan Konseptual Volume 6 Nomor 2, Mei 2021 
mempunyai dasar dalam mempelajari konsep matematika yang lebih tinggi. Selain itu, dengan pemahaman konsep siswa bisa terbantu dalam menyelesaikan masalah matematika (Sumaji dkk., 2020). Sehingga dapat disimpulkan bahwa pemahaman konsep merupakan salah satu keterampilan penting yang harus dimiliki dalam mempelajari Matematika.

Siswa yang memahami konsep dengan baik akan mampu mendefinisikan konsep dengan kalimatnya sendiri, mengklasifikasikan objek berdasarkan persyaratan tertentu, mengidentifikasi sifat-sifat operasi atau konsep, menerapkan konsep, memberi contoh atau bukan contoh dari suatu konsep, menyajikan konsep dalam berbagai representasi, mengaitkan konsep yang satu dengan yang lain, dan mengembangkan syarat perlu dan syarat cukup suatu konsep (Aledya, 2019; Mulyono \& Hapizah, 2018; Kholid dkk., 2020). Sehingga dalam mempelajari matematika, siswa harus memahami konsep terlebih dahulu agar dapat menyelesaikan soal dan selanjutnya dapat mengaplikasikan konsep dalam dunia nyata serta mengembangkan kemampuan lain yang menjadi tujuan pembelajaran matematika. Dengan mengetahui pentingnya pemahaman konsep dalam pembelajaran matematika maka keterampilan ini perlu ditingkatkan demi keberhasilan belajar siswa, karena keefektifan pembelajaran juga dapat dilihat dari kualitas pemahaman konsep matematika yang diperoleh (Afriyani dkk., 2018).

Salah satu konsep penting dalam pembelajaran Matematika adalah matriks. Berdasarkan Standart Isi pada Kurikulum 2013 revisi 2017, materi matriks mulai diajarkan pada jenjang SMA/MA pada mata pelajaran Matematika Wajib kelas XI. Menurut Aminullah (2018), matriks merupakan salah satu bentuk representasi matematika yang berupa susunan bilangan-bilangan dalam bentuk baris dan kolom yang membentuk suatu persegi atau persegi panjang dan penulisannya dibatasi oleh kurung siku atau kurung biasa. Materi ini merupakan salah satu materi yang terkait erat dengan kehidupan siswa, misalkan dalam menyelesaikan masalah persamaan linear dan analisis dalam bidang ekonomi, statistika, pendidikan, manajemen, kimia dan bidang teknologi lainnya (Zahara dkk., 2020). Sehingga pemahaman konsep matriks siswa perlu ditingkatkan dalam pembelajaran matematika di sekolah agar nantinya siswa dapat mengaplikasikan konsep yang sudah dipahami dalam segala bidang kehidupannya.

Masa pandemic Covid-19 sejak bulan Mei 2020 yang melanda Indonesia telah mengubah tatanan pendidikan di Indonesia, yaitu kegiatan pembelajaran yang semula dilakukan secara tatap muka langsung di kelas, diganti dengan kegiatan pembelajaran daring yang dilakukan dari rumah masing-masing atau dikenal dengan istilah Work From Home (Azzahra, 2020). MAN Kota Batu merupakan salah satu madrasah yang menerapkan pembelajaran daring untuk siswanya secara umum pada semester Ganjil Tahun Ajaran 2020/2021. Berdasarkan observasi di lapangan, pembelajaran untuk semua mata pelajaran terpusat di e-learning madrasah. Berdasarkan hasil wawancara dengan guru mata pelajaran Matematika kelas XI IPS 2 MAN Kota Batu, guru memanfaatkan fitur Bahan Ajar untuk mengupload e-book, modul, dan penugasan untuk siswa. Siswa belajar melalui e-book dan modul kemudian menyelesaikan soal penugasan yang diberikan. Apabila mengalami kesulitan, siswa bisa bertanya melalui timeline $e$ learning atau whatsapp.

Berdasarkan hasil monitoring di e-learning, banyak siswa yang hanya melakukan konfirmasi kehadiran saja tanpa melakukan hal lain sesuai instruksi

310 BRILIANT: Jurnal Riset dan Konseptual Volume 6 Nomor 2, Mei 2021 
yang diberikan misalnya membaca metode dan tujuan pembelajaran yang akan dilakukan yang ditulis guru di timeline dan membaca atau mendownload bahan ajar yang dibagikan guru. Selain itu, siswa juga masih sedikit yang bertanya pada saat pembelajaran, baik melalui e-learning maupun whatsapp. Selain itu, berdasarkan hasil tes yang dilakukan guru pada akhir pembelajaran diperoleh ratarata nilai pemahaman konsep siswa kelas XI IPS 2 MAN Kota Batu masih kurang. Masalah ini perlu segera diselesaikan karena dikhawatirkan akan menghambat pemahaman konsep yang lain, mengingat ide-ide Matematika yang terkait satu dengan yang lain (Aledya, 2019; Dewiyani, 2009). Upaya yang diharapkan dapat meningkatkan pemahaman konsep siswa adalah menentukan model pembelajaran yang sesuai dengan karakteristik siswa serta situasi dan kondisi saat ini. Berdasarkan beberapa penelitian, salah satu model pembelajaran yang terbukti dapat meningkatkan pemahaman konsep siswa adalah pembelajaran kooperatif (Wisra, 2019).

Pembelajaran kooperatif merupakan suatu model pembelajaran di mana siswa dikondisikan untuk saling berinteraksi dalam menyelesaikan masalah dengan bermacam-macam strategi yang berbeda (Prasetyo et al., 2019). Salah satu tipe pembelajaran kooperatif yang memiliki beberapa kelebihan adalah pembelajaran kooperatif tipe Group Investigation (GI). Beberapa karakteristik pembelajaran kooperatif tipe GI yang menjadi kelebihan dari tipe pembelajaran ini yaitu adanya kelompok heterogen, siswa memiliki kesempatan untuk memilih topik yang diinvestigasi, merencanakan, melaksanakan, mempresentasikan dan mengevaluasi hasilnya (Ayuwanti, 2017; Yemi dkk., 2018). Selain itu, melalui pembelajaran kooperatif GI siswa terlatih untuk percaya diri dalam bersosialisasi, memecahkan masalah, berdemokrasi dalam menyatukan dan mengonstruk pemahaman konsep (Laila \& Al Ayubi, 2018; Retno, 2014).

Sejauh ini banyak penelitian tentang pembelajaran kooperatif tipe GI dalam upaya meningkatkan pemahamaan konsep siswa. Penelitian dalam bidang Matematika misalkan penelitian yang dilakukan oleh (Ayuwanti, 2017; Laila \& Al Ayubi, 2018; Lestari, 2017; Retno, 2014). Penelitian-penelitian ini memberikan hasil salah satunya adalah meningkatnya pemahaman konsep siswa dengan pembelajaran kooperatif tipe GI. Namun, pada masa WFH saat ini diperlukan media pembelajaran untuk memfasilitasi kegiatan diskusi dan presentasi kelompok investigasi.

Pada era Pendidikan 4.0 saat ini banyak pilihan media pembelajaran yang dapat digunakan untuk menunjang kegiatan pembelajaran daring. Beberapa media pembelajaran daring yang telah terbukti efektif dalam meningkatkan pemahaman konsep siswa misalnya adalah E-learning, Blended E-learning, Web-based Learning Blog, Google Classroom, Edmodo, Google Form, Web Blog Pribadi, DMS Geogebra, E-book dan Microsoft Office 365 (Amany \& Desire, 2020; Napratilora dkk., 2020; Zengin \& Tatar, 2017). Penggunaan masing-masing media disesuaikan dengan situasi dan kondisi pembelajaran yang akan dilakukan.

Microsoft Teams merupakan salah satu bagian dari rangkaian Office 365 yang bisa digunakan sebagai media untuk bertemu dan berdiskusi secara virtual, berbagi file dan kolaborasi file di manapun dan kapanpun serta dapat merekam sesi kelas (Poston dkk., 2020; Pradja \& Baist, 2019; Schumann Eriksson, 2020). Sehingga dengan menggunakan Microsoft Teams ini juga sangat memungkinkan dilakukan pembelajaran kooperatif daring tipe GI.

311 BRILIANT: Jurnal Riset dan Konseptual Volume 6 Nomor 2, Mei 2021 
Sampai saat ini, belum ada penelitian terkait dengan penggunaan model pembelajaran kooperatif GI dengan media Microsoft Teams yang diterapkan pada pembelajaran daring di masa pandemic Covid-19, terutama di madrasah tempat peneliti mengajar selama ini. Sehingga, dengan mengetahui pentingnya pemahaman konsep matematika khususnya pada konsep matriks dan melihat situasi dan kondisi pembelajaran saat ini maka diperlukan penelitian tentang bagaimana perbedaan pembelajaran kooperatif daring tipe GI berbantuan Microsoft Teams terhadap pemahaman konsep matriks siswa kelas XI MAN Kota Batu.

\section{METODE}

Jenis rancangan penelitian yang sesuai dengan judul dan permasalahan yang akan diteliti adalah quasi experimental design (Creswell, 2012) dengan menggunakan satu kelas eksperimen dan satu kelas kontrol. Subjek penelitiannya adalah kelas XI IPS 2 dan XI IPS 3 MAN Kota Batu Semester Ganjil Tahun Pelajaran 2020/2021 yang mengikuti pembelajaran daring. Siswa kelas XI IPS 2 yang mengikuti pembelajaran daring terdiri dari 25 siswa (6 siswa laki-laki dan 19 siswa perempuan), sedangkan kelas XI IPS 3 terdiri dari 25 siswa (7 siswa lakilaki dan 18 siswa perempuan). Kelas XI IPS 2 sebagai kelas eksperimen dan kelas XI IPS 3 sebagai kelas kontrol.

Ada dua variabel yang digunakan dalam penelitian yaitu pembelajaran Matematika dengan menerapkan pembelajaran kooperatif daring tipe GI berbantuan Microsoft Teams sebagai variabel bebas (independent variable) dan kemampuan pemahaman konsep matriks siswa sebagai variabel terikat (dependent variable). Penelitian ini bertujuan untuk mengetahui perbedaan kemampuan pemahaman konsep siswa pada kelas eksperimen dan kelas kontrol dengan menggunakan tes pemahaman konsep materi matriks setelah dilakukan perlakuan. Soal tes uraian dikembangkan berdasarkan 8 indikator pemahaman konsep menurut Permendikbud Nomor 59 Tahun 2014. Desain penelitian disajikan dalam Tabel 1 berikut.

Tabel 1. Quasi Experimental Design

\begin{tabular}{llll}
\hline Kelas & Pre-test & Variabel Terikat & Post-test \\
\hline Eksperimen & $\mathrm{O} 1$ & $\mathrm{X} 1$ & $\mathrm{P} 1$ \\
\hline Kontrol & $\mathrm{O} 2$ & - & $\mathrm{P} 2$ \\
\hline
\end{tabular}

Keterangan Tabel 1:

O1 = Kemampuan pemahaman konsep awal (pre-test) kelas eksperimen

$\mathrm{O} 2$ = Kemampuan pemahaman konsep awal (pre-test) kelas kontrol

$\mathrm{X} 1$ = Perlakuan kelas eksperimen (pembelajaran kooperatif daring tipe GI berbantuan Microsoft Teams)

P1 = Kemampuan pemahaman konsep kelas eksperimen setelah pembelajaran kooperatif daring tipe GI berbantuan Microsoft Teams (post-test)

P2 = Kemampuan pemahaman konsep akhir (post-test) kelas kontrol setelah pembelajaran konvensional

Analisis data yang akan dilakukan dalam penelitian ini ada 2 yaitu analisis tahap awal dan analisis tahap akhir. Analisis tahap awal dilakukan sebelum perlakuan (pembelajaran kooperatif daring tipe GI berbantuan Microsoft

312 BRILIANT: Jurnal Riset dan Konseptual

Volume 6 Nomor 2, Mei 2021 
Teams). Sebelum subjek diberi perlakuan, maka data awal subjek perlu dianalisis dahulu melalui uji normalitas dan uji homogenitas, untuk selanjutnya dilakukan uji-T. Hal ini dilakukan untuk mengetahui apakah kedua subjek berasal dari kondisi awal yang sama. Data yang digunakan dalam analisis tahap awal berasal dari nilai Penilaian Harian materi sebelumnya (pre-test).

Analisis tahap akhir dilakukan setelah subjek diberi perlakuan. Analisis tahap akhir merupakan analisis untuk menguji hipotesis penelitian menggunakan uji hipotesis setelah kedua sampel diberi perlakuan yang berbeda. Sebelum uji hipotesis terlebih dahulu dilakukan pengujian prasyarat analisis yaitu uji normalitas dan uji homogenitas. Setelah data dinyatakan normal dan homogen, selanjutnya dilakukan uji hipotesis yaitu uji- $T$ untuk mengetahui seberapa jauh pengaruh variabel independen terhadap variabel dependen. Pengolahan data akan dilakukan dengan menggunakan alat bantu aplikasi software Minitab - Uji Statistik versi 16.4.2.2 agar analisis data yang dihasilkan lebih akurat. Hipotesis yang digunakan adalah sebagai berikut.

$\mathrm{H}_{0}$ : pemahaman konsep matriks siswa dalam pembelajaran kooperatif daring tipe GI dengan Microsoft Teams sama dengan pemahaman konsep siswa dalam pembelajaran konvensional

$\mathrm{H}_{1}$ : pemahaman konsep matriks siswa dalam pembelajaran kooperatif daring tipe GI dengan Microsoft Teams berbeda dengan pemahaman konsep siswa dalam pembelajaran konvensional

Selain analisis data hasil pre-test dan post-test, dilakukan juga analisis data hasil observasi. Analisis ini digunakan untuk memperoleh informasi tentang proses pengelolaan pembelajaran menggunakan model pembelajaran kooperatif daring tipe Group Investigation (GI) berbantuan Microsoft Teams di kelas eksperimen. Observasi dilakukan terhadap proses pembelajaran untuk melihat kesesuaiannya dengan Rencana Pelaksanaan Pembelajaran (RPP) dan mengetahui respon siswa terhadap pembelajaran yang dilakukan. Secara umum, kegiatan pembelajaran yang akan dilakukan dikembangkan dari langkah-langkah pembelajaran kooperatif tipe GI menurut Ayuwanti (2017) yaitu seperti yang tergambar dalam Tabel 2. Pada tabel tersebut dijelaskan secara garis besar kegiatan inti yang dilakukan oleh guru dan siswa beserta rencana implementasinya.

Tabel 2. Kegiatan Inti Pembelajaran Kooperatif Daring Tipe GI Berbantuan Microsoft Teams

\begin{tabular}{|c|c|c|}
\hline $\begin{array}{c}\text { Langkah-langkah } \\
\text { Pembelajaran }\end{array}$ & Kegiatan Guru dan Siswa & Rencana Implementas \\
\hline $\begin{array}{l}\text { Tahap 1: } \\
\text { Mengidentifikasi } \\
\text { topik dan membagi } \\
\text { siswa ke dalam } \\
\text { kelompok. }\end{array}$ & 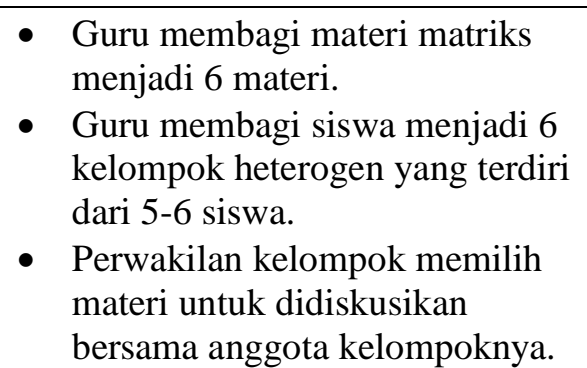 & $\begin{array}{l}\text { Pertemuan } 1 \text { melalui } \\
\text { whatsapp grup kelas }\end{array}$ \\
\hline
\end{tabular}

313 BRILIANT: Jurnal Riset dan Konseptual Volume 6 Nomor 2, Mei 2021 


\begin{tabular}{|c|c|c|}
\hline $\begin{array}{l}\text { Langkah-langkah } \\
\text { Pembelajaran }\end{array}$ & Kegiatan Guru dan Siswa & Rencana Implementasi \\
\hline $\begin{array}{l}\text { Tahap 2: } \\
\text { Pemilihan topik dan } \\
\text { perencanaan tugas. }\end{array}$ & $\begin{array}{l}\text { - Siswa dalam kelompok membagi } \\
\text { materi untuk dicari setiap } \\
\text { anggota } \\
\text { - Siswa dalam kelompok membuat } \\
\text { kesepakatan tentang sumber } \\
\text { yang akan digunakan mencari } \\
\text { materi }\end{array}$ & $\begin{array}{l}\text { Pertemuan } 1 \text { melalui } \\
\text { whatsapp grup kelas } \\
\text { dengan memperhatikan } \\
\text { LKK masing-masing. }\end{array}$ \\
\hline $\begin{array}{l}\text { Tahap 3: } \\
\text { Melaksanakan } \\
\text { investigasi }\end{array}$ & $\begin{array}{l}\text { Siswa mengumpulkan materi, } \\
\text { menganalisis dan mengevaluasi } \\
\text { informasi, membuat kesimpulan dan } \\
\text { mengaplikasikan materi sesuai } \\
\text { pembagian mereka ke dalam } \\
\text { pengetahuan baru dalam mencapai } \\
\text { solusi masalah kelompok }\end{array}$ & $\begin{array}{l}\text { Pertemuan } 1 \text { dan } \\
\text { sebelum presentasi } \\
\text { melalui grup whatsapp } \\
\text { kelompok }\end{array}$ \\
\hline $\begin{array}{l}\text { Tahap 4: } \\
\text { Menyiapkan materi } \\
\text { presentasi }\end{array}$ & $\begin{array}{l}\text { Siswa bersama kelompok menyusun } \\
\text { materi presentasi yang sudah } \\
\text { diperoleh sesuai urutan materi pada } \\
\text { LKK }\end{array}$ & $\begin{array}{l}\text { Pertemuan } 1 \text { dan } \\
\text { sebelum presentasi } \\
\text { melalui grup whatsapp } \\
\text { kelompok }\end{array}$ \\
\hline $\begin{array}{l}\text { Tahap 5: } \\
\text { Mempresentasikan } \\
\text { hasil diskusi }\end{array}$ & $\begin{array}{l}\text { - Siswa dalam kelompok } \\
\text { mempresentasikan hasil kerjanya } \\
\text { dengan memanfaatkan Microsoft } \\
\text { Teams. } \\
\text { - Siswa yang lain menyimak dan } \\
\text { menanggapi materi presentasi } \\
\text { yang disampaikan kelompok } \\
\text { presentasi }\end{array}$ & $\begin{array}{l}\text { Pada setiap pertemuan } \\
\text { mulai dari pertemuan } 2 \text {, } \\
\text { dan seterusnya (Setiap } \\
\text { pertemuan presentasi } 1 \\
\text { kelompok) melalui } \\
\text { Microsoft Teams }\end{array}$ \\
\hline $\begin{array}{l}\text { Tahap 6: } \\
\text { Evaluasi }\end{array}$ & $\begin{array}{l}\text { Siswa diberikan post-test } \\
\text { pemahaman konsep matriks. }\end{array}$ & Pada pertemuan ke-5 \\
\hline
\end{tabular}

\section{HASIL DAN PEMBAHASAN}

Analisis tahap awal dilakukan terhadap pemahaman konsep awal kedua kelas subjek penelitian berdasarkan hasil Penilaian Harian pemahaman konsep pada materi sebelumnya (pre-test). Hal ini dilakukan untuk melihat kesetaraan dua kelas sebagai subjek penelitian (kelas eksperimen dan kelas kontrol). Rekap hasil pemahaman konsep awal (pre-test) kedua kelas yang diperoleh dengan menggunakan software Minitab 16.4.2.2 disajikan pada Tabel 3 berikut.

Tabel 3. Rekap Hasil Pemahaman Konsep Awal (Pre-test) Kelas Eksperimen dan Kelas Kontrol

\begin{tabular}{lcc}
\hline \multicolumn{1}{c}{ Hasil } & $\begin{array}{c}\text { Kelas Eksperimen } \\
\text { (XI IPS 2) }\end{array}$ & $\begin{array}{c}\text { Kelas Kontrol } \\
\text { (XI IPS 3) }\end{array}$ \\
\hline N (jumlah siswa) & 25 & 25 \\
\hline Nilai maksimum & 100 & 100 \\
\hline Nilai minimum & 20 & 35 \\
\hline Mean & 60 & 62 \\
\hline Median & 57 & 65 \\
\hline Modus & 40 & 70 \\
\hline Standar Deviasi & 21,29 & 19,01 \\
\hline
\end{tabular}

314 BRILIANT: Jurnal Riset dan Konseptual Volume 6 Nomor 2, Mei 2021 


\begin{tabular}{lcc}
\hline \multicolumn{1}{c}{ Hasil } & $\begin{array}{c}\text { Kelas Eksperimen } \\
\text { (XI IPS 2) }\end{array}$ & $\begin{array}{c}\text { Kelas Kontrol } \\
\text { (XI IPS 3) }\end{array}$ \\
\hline$P$-Value (Kolmogorov-Smirnov) & 0,150 & 0,100 \\
\hline$P$-Value (Uji-Lavene) & \multicolumn{3}{c}{0,749} \\
\hline$P$-Value (Uji-T) & \multicolumn{3}{c}{0,759} \\
\hline
\end{tabular}

Untuk mengetahui normalitas data nilai kemampuan pemahaman konsep matematika siswa pada pre-test untuk setiap kelas digunakan uji KolmogorovSmirnov (K-S). Hipotesis yang diuji adalah $\mathrm{H}_{0}$ : sampel berdistribusi normal, melawan alternatif $\mathrm{H}_{1}$ : sampel tidak berdistribusi normal, dengan kriteria pengujian jika nilai probabilitas ( $P$-Value) lebih besar dari $\alpha=0,05$ maka hipotesis nol diterima. Berdasarkan Tabel 3 terlihat bahwa nilai probabilitas $P$ Value (Kolmogorov-Smirnov) kelas eksperimen adalah 0,150 dan kelas kontrol adalah 0,100 , masing-masing lebih dari $\alpha=0,05$ yang berarti hipotesis nol diterima. Dengan demikian, data pre-test nilai pemahaman konsep awal siswa berdistribusi normal.

Selanjutnya dilakukan uji homogenitas data nilai pemahaman konsep awal siswa pada masing-masing kelas dengan menggunakan uji-Lavene. Hipotesis yang diuji adalah $\mathrm{H}_{0}: \sigma_{1}=\sigma_{2}$ melawan alternatif $\mathrm{H}_{1}: \sigma_{1} \neq \sigma_{2}$, dengan kriteria pengujian adalah jika nilai probabilitas $P$-Value (Uji-Lavene) lebih dari $\alpha=0,05$, maka hipotesis nol diterima. Berdasarkan Tabel 3 terlihat bahwa nilai probabilitas $P$-Value (Uji-Lavene) adalah 0,749 atau lebih dari $\alpha$ berarti hipotesis nol diterima. Dengan demikian, varians data pre-test nilai pemahaman konsep awal siswa kelas eksperimen dan kelas kontrol adalah homogen. Oleh karena nilai pre-test kedua kelas berdistribusi normal dan variansnya homogen, maka untuk mengetahui ada tidaknya perbedaan rata-rata data pre-test kedua kelas digunakan uji- $T$ dua arah. Hasil uji- $T$ dua arah dengan menggunakan minitab diperoleh nilai probabilitas $P$ Value (Uji-T) 0,759 atau lebih dari $\alpha$. Ini berarti varians data pre-test kelas eksperimen dan kelas kontrol adalah sama atau tidak ada perbedaan rata-rata kedua kelas. Sehingga dapat dikatakan bahwa kemampuan awal kedua kelas yang digunakan dalam penelitian (kelas eksperimen dan kelas kontrol) adalah relatif sama. Selanjutnya, kedua kelas ekperimen dan kelas kontrol diberi perlakuan yang berbeda. Kelas eksperimen diberi perlakuan berupa pembelajaran kooperatif daring tipe GI berbantuan Microsoft Teams sesuai rencana pembelajaran yang telah dirancang sebelumnya pada metodologi penelitian. Sedangkan kelas kontrol diberi perlakuan pembelajaran konvensional menggunakan e-book dan modul yang sebelumnya sudah digunakan guru mata pelajaran pada kelas yang bersangkutan. Pembelajaran untuk kedua kelas dilakukan pada tanggal $1-29$ Oktober 2020 sebanyak 5 pertemuan, dengan alokasi waktu 4 JP/pertemuan (30 menit/JP). Materi yang diajarkan pada kedua kelas adalah sama, yaitu tentang matriks yang meliputi definisi, jenis, transpose, kesamaan dan operasi matriks. Setelah diberi perlakuan yang berbeda antara kelas eksperimen dan kontrol, selanjutnya pada pertemuan terakhir setelah materi tersampaikan siswa diberi tes pemahaman konsep yang sama pada akhir pembelajaran (post-test). Soal tes pemahaman konsep dikembangkan berdasarkan indikator pemahaman konsep menurut Permendikbud Nomor 59 Tahun 2014. Soal terdiri dari 8 butir soal uraian yang mewakili setiap indikator. Setelah hasil pekerjaan siswa dikoreksi, hasilnya dianalisis untuk mengetahui perbedaaan hasil yang diperoleh kedua kelas eksperimen dan kelas kontrol. Rekap hasil tes pemahaman konsep matriks kedua

315 BRILIANT: Jurnal Riset dan Konseptual Volume 6 Nomor 2, Mei 2021 
kelas yang diperoleh dengan menggunakan software Minitab disajikan sebagai berikut.

Tabel 4. Rekap Hasil Post-test Pemahaman Konsep Matriks Kelas Eksperimen dan Kelas Kontrol

\begin{tabular}{lcc}
\hline \multicolumn{1}{c}{ Hasil } & $\begin{array}{c}\text { Kelas Eksperimen } \\
\text { (XI IPS 2) }\end{array}$ & $\begin{array}{c}\text { Kelas Kontrol } \\
\text { (XI IPS 3) }\end{array}$ \\
\hline $\mathrm{N}$ (jumlah siswa) & 25 & 25 \\
\hline Nilai maksimum & 93 & 84 \\
\hline Nilai minimum & 55 & 45 \\
\hline Mean & 75 & 61 \\
\hline Median & 75 & 61 \\
\hline Modus & 75 & 55 \\
\hline Standar Deviasi & 9,578 & 0,084 \\
\hline$P$-Value (Kolmogorov-Smirnov) & 0,182 & 0,116 \\
\hline$P$-Value (Uji-Lavene) & \multicolumn{2}{c}{0,675} \\
\hline$P$-Value (Uji-T) & \multicolumn{2}{c}{0,000} \\
\hline
\end{tabular}

Berdasarkan nilai pemahaman konsep awal (pre-test) dan setelah perlakuan (post-test) untuk kelas eksperimen, terlihat bahwa ada beberapa item yang meningkat, tetapi ada beberapa item juga yang menurun. Beberapa item yang mengalami peningkatan adalah nilai minimum, mean, median dan modus. Sedangkan item yang mengalami penurunan adalah nilai maksimum dan standart deviasi. Rincian kenaikan dan penurunan untuk setiap item adalah sebagai berikut: nilai maksimum turun 7 poin, nilai minimum naik 35 poin, mean naik 15 poin, median naik 18 poin, modus naik 35 poin dan standart deviasi turun signifikan.

Berdasarkan nilai pemahaman konsep awal (pre-test) dan tes akhir (posttest) untuk kelas kontrol, hanya ada satu item yang meningkat yaitu nilai minimum, sedangkan item yang lainnya menurun. Rincian kenaikan dan penurunan untuk setiap item adalah sebagai berikut: nilai maksimum turun 16 poin, nilai minimum naik 10 poin, mean turun 1 poin, median turun 4 poin, modus turun 15 poin dan standart deviasi turun signifikan. Sehingga dapat disimpulkan bahwa secara umum kemampuan pemahaman konsep siswa mengalami penurunan, walaupun nilai menimumnya mengalami peningkatan. Akan tetapi keragaman nilai siswa dapat dikatakan meningkat karena standart deviasi mengalami penurunan. Untuk mengetahui ada atau tidaknya perbedaaan yang signifikan selanjutnya digunakan uji- $T$ dua jalur untuk data nilai post-test kedua kelas, tetapi sebelumnya dilakukan uji persyaratan yaitu uji normalitas distribusi data dan uji homogenitas varians. Untuk uji normalitas distribusi data digunakan uji Kolmogorov-Smirnov (K-S). Hipotesis yang diuji adalah $\mathrm{H}_{0}$ : sampel berdistribusi normal, melawan alternatif $\mathrm{H}_{1}$ : sampel tidak berdistribusi normal, dengan kriteria pengujian berikut: jika nilai probabilitas $(P$-Value $)$ lebih dari $\alpha=0,05$ maka hipotesis nol diterima.

Sesuai rekapan data pada Tabel 4, diperoleh $P$-Value hasil uji normalitas dengan uji Kolmogorov-Smirnov (K-S) untuk kelas eksperimen 0,182 dan untuk kelas kontrol 0,116. Nilai untuk kedua kelas ini masing-masing lebih besar dari $\alpha=0,05$, yang artinya hipotesis nol diterima. Dengan demikian, data post-test nilai pemahaman konsep matriks siswa kedua kelas berdistribusi normal. Selanjutnya dilakukan uji homogenitas data nilai pemahaman konsep matriks siswa pada masing-masing kelas dengan menggunakan uji-Lavene. Hipotesis yang

316 BRILIANT: Jurnal Riset dan Konseptual

Volume 6 Nomor 2, Mei 2021 
diuji adalah $\mathrm{H}_{0}: \sigma_{1}=\sigma_{2}$ melawan alternatif $\mathrm{H}_{1}: \sigma_{1} \neq \sigma_{2}$, dengan kriteria pengujian adalah jika nilai probabilitas $(P$-Value $)$ lebih besar dari $\alpha=0,05$, maka hipotesis nol diterima. Berdasarkan uji yang dilakukan pada software Minitab diperoleh nilai $P$-Value $=0,675$ lebih dari $\alpha$, yang berarti hipotesis nol diterima. Dengan demikian, varians data post-test nilai pemahaman konsep matriks siswa kelas eksperimen dan kelas kontrol adalah homogen. Oleh karena nilai post-test kedua kelas berdistribusi normal dan variansnya homogen, maka untuk mengetahui ada tidaknya perbedaan rata-rata data post-test kedua kelas digunakan uji- $T$ dua arah. Berdasarkan Tabel 4 , hasil uji- $T$ dua arah dengan menggunakan minitab diperoleh nilai probabilitas (P-Value) 0,000 atau kurang dari $\alpha=0,05$. Ini berarti varians data post-test kelas eksperimen dan kelas kontrol adalah berbeda atau ada perbedaan rata-rata kedua kelas.

Sedangkan berdasarkan observasi yang dilakukan selama penelitian, siswa pada kelas eksperimen aktif dalam kegiatan pembelajaran. Hal ini terlihat pada monitoring di e-learning, sebagian besar siswa aktif mengeksplore timeline dan bahan ajar yang dibagikan guru. Pada kegiatan diskusi dan presentasi melalui grup whatsapp dan Microsoft Teams siswa juga aktif bertanya dan mengemukakan pendapatnya. Siswa secara individu maupun kelompok menyelesaikan tugas-tugas yang diberikan dengan tertib, sehingga kegiatan pembelajaran berjalan sesuai rencana dan alokasi waktu yang telah dibuat. Keaktifan siswa dalam pembelajaran ini mungkin juga berkontribusi dalam meningkatkan pemahaman konsep siswa. Pada pembelajaran kelas kontrol, siswa terlihat kurang aktif dalam pembelajaran. Hal ini terlihat pada monitoring di $e$ learning, masih banyak siswa belum begitu aktif mengeksplore timeline dan bahan ajar yang dibagikan guru. Pada saat memahami materi, latihan soal dan mengerjakan tugas siswa masih sedikit yang bertanya kepada guru berkaitan dengan materi dan tugas yang diberikan. Siswa juga masih banyak yang telat mengumpulkan tugas dan hasil pekerjaannya juga masih banyak kesalahan. Ketidakaktifan ini yang kemungkinan besar menyebabkan kurangnya hasil tes pemahaman konsep yang diperoleh siswa kelas kontrol pada post-test.

Berdasarkan data dan analisis data hasil pre-test dan post-test siswa setelah pembelajaran kooperatif daring tipe GI dengan Microsoft Teams, dapat disimpulkan bahwa kemampuan pemahaman konsep matriks siswa mengalami peningkatan yang signifikan. Hal ini menguatkan beberapa hasil penelitian sebelumnya tentang meningkatnya pemahaman konsep matematika siswa setelah pembelajaran kooperatif tipe GI (Ayuwanti, 2017; Laila \& Al Ayubi, 2018; Lestari, 2017; Retno, 2014). Apabila data hasil post-test siswa setelah pembelajaran kooperatif daring tipe GI dengan Microsoft Teams dibandingkan dengan hasil post-test siswa setelah pembelajaran konvensional, maka terlihat jelas bahwa nilai yang diperoleh siswa setelah pembelajaran kooperatif daring tipe GI dengan Microsoft Teams lebih baik daripada siswa pada pembelajaran konvensional. Sehingga dapat dikatakan bahwa terdapat pengaruh pembelajaran kooperatif daring tipe GI berbantuan Microsoft Teams terhadap kemampuan pemahaman konsep matriks siswa. Hal ini sesuai dengan hasil penelitian yang telah dilakukan oleh (Laili, 2019; Wisra, 2019; Yuliani dkk., 2018) yaitu terdapat perbedaan yang signifikan antara kemampuan pemahaman konsep matematis siswa yang belajar menggunakan model kooperatif tipe GI dengan siswa yang

317 BRILIANT: Jurnal Riset dan Konseptual Volume 6 Nomor 2, Mei 2021 
belajar menggunakan pembelajaran konvensional. Dan lebih jauh lagi dapat disimpulkan bahwa kemampuan pemahaman konsep matriks siswa setelah pembelajaran kooperatif daring tipe GI berbantuan Microsoft Teams lebih baik daripada kemampuan pemahaman konsep matriks siswa setelah pembelajaran konvensional. Hasil ini menguatkan hasil temuan penelitian yang telah dilakukan oleh (Laili, 2019; Wisra, 2019; Yuliani dkk., 2018).

Pembelajaran kooperatif daring tipe GI dengan Microsoft Teams selain berpengaruh terhadap kemampuan pemahaman konsep siswa, ternyata juga berpengaruh terhadap keaktifan siswa di kelas selama pembelajaran. Berdasarkan analisis data hasil observasi kegiatan pembelajaran dapat disimpulkan bahwa siswa pada pembelajaran kooperatif daring tipe GI berbantuan Microsoft Teams lebih aktif daripada siswa pada pembelajaran konvensional. Hal ini menguatkan hasil penelitian sebelumnya tentang pembelajaran kooperatif GI juga berpengaruh positif terhadap keaktifan siswa di kelas (Ayuwanti, 2017; Laila \& Al Ayubi, 2018; Lestari, 2017; Roestika dkk., 2019).

\section{KESIMPULAN}

Berdasarkan hasil analisis dan pembahasan yang telah dikemukakan sebelumnya, diperoleh beberapa kesimpulan sebagai berikut. Pertama bahwa terdapat peningkatan kemampuan pemahaman konsep siswa setelah pembelajaran kooperatif daring tipe GI berbantuan Microsoft Teams. Kedua bahwa terdapat perbedaan kemampuan pemahaman konsep matriks siswa yang memperoleh pembelajaran kooperatif daring tipe GI berbantuan Microsoft Teams dengan siswa yang memperoleh pembelajaran konvensional. Dan ketiga bahwa kemampuan pemahaman konsep matriks siswa pada kelas yang memperoleh pembelajaran kooperatif daring tipe GI berbantuan Microsoft Teams lebih baik daripada siswa yang memperoleh pembelajaran konvensional.

\section{SARAN}

Berdasarkan kesimpulan dari penelitian ini, dapat dikemukakan saran berikut. Pertama, pembelajaran kooperatif daring tipe GI berbantuan Microsoft Teams hendaknya terus dikembangkan di lapangan dan dijadikan sebagai alternatif pilihan guru dalam pembelajaran matematika. Hal ini dikarenakan pembelajaran ini telah terbukti dapat meningkatkan kemampuan pemahaman konsep matriks siswa. Kedua, dalam mengimplementasikan pembelajaran kooperatif daring tipe GI berbantuan Microsoft Teams untuk meningkatkan pemahaman konsep matriks siswa, guru harus mempertimbangkan kemampuan awal siswa dan juga mempertimbangkan pilihan media yang tepat agar hasil yang dicapai lebih optimal. Ketiga, sebagai guru matematika khususnya sebaiknya mengadakan perubahan-perubahan secara bertahap dalam pembelajaran sesuai dengan situasi, kondisi dan kemampuan siswa agar pembelajaran lebih menarik dan tidak membosankan. Keempat, oleh karena penelitian ini terbatas pada materi matriks, maka diharapkan ada penelitian selanjutnya yang meneliti tentang model pembelajaran kooperatif daring tipe GI berbantuan Microsoft Teams terhadap pemahaman konsep matematika yang lain dan lebih luas lagi agar bisa diterapkan pada konsep di luar matematika.

318 BRILIANT: Jurnal Riset dan Konseptual Volume 6 Nomor 2, Mei 2021 


\section{DAFTAR RUJUKAN}

Afriyani, D., Sa'dijah, C., Subanji, \& Muksar, M. (2018). Characteristics of Students ' Mathematical Understanding in Solving Multiple Representation Task based on Solo Taxonomy. 13(3), 281-287.

Aledya, V. (2019). Kemampuan Pemahaman Konsep Matematika pada Siswa. May, 0-7.

Amany, D., \& Desire, A. (2020). Pembelajaran Interaktif berbasis Gamifikasi guna Mendukung Program WFH pada saat Pandemic Covid-19. ADI Bisnis Digital Interdisiplin Jurnal, 48-55.

Aminullah. (2018). Analisis Kesulitan Mahasiswa Dalam Menyelesaikan Soal Matriks. Logaritma: Jurnal Ilmu-Ilmu Pendidikan Dan Sains, 6(01), 64.

Ardianto, W., \& Kuswandi, D. (2017). Pembelajaran Saintifik Berbantuan Media Manipulatif untuk Memahamkan Konsep Penjumlahan dan Pengurangan Bilangan Bulat. Jurnal Pendidikan - Teori, Penelitian, Dan Pengembangan, 694-705.

Ayuwanti, I. (2017). Meningkatkan Aktivitas dan Hasil Belajar Matematika Menggunakan Model Pembelajaran Kooperatif Tipe Group Investigation di SMK Tuma'ninah Yasin Metro. SAP (Susunan Artikel Pendidikan), 1(2), $105-114$.

Azzahra, N. (2020). Mengkaji Hambatan Pembelajaran Jarak Jauh di Indonesia di Masa Pandemi Covid-19. 19(2), 1-9.

Creswell, J. W. (2012). Education Research (Fourth Edi). Lincoln: University of Nebraska.

Dewiyani, M. J. (2009). Karakteristik Proses Berpikir Siswa Dalam Mempelajari. Prosiding Seminar Nasional Penelitian, Pendidikan Dan Penerapan MIPA Fakultas MIPA, Universitas Negeri Yogyakarta, 16 Mei 2009, 481-492.

Kemendikbud. (2013). Lampiran Permendikbud Nomor 81A Tahun 2013 tentang Implementasi Kurikulum Pedoman Umum Pembelajaran.

Kholid, M. N., Sadijah, C., Hidayanto, E., Permadi, H., \& Firdareza, R. M. F. (2020). Pupils' Reflective Thinking in Solving Linear Equation System Problem. Journal for the Mathematics Education and Teaching Practices, $1(1), 19-27$.

Laila, N., \& Al Ayubi, S. (2018). Volume 3 No 2 Juli 2018. AXIOMA Jurnal Program Studi Pendidikan Matematika Universitas Islam Jember, 3(2), $158-167$.

Laili, S. I. (2019). Efektifitas Model Problem Based Learning dan Model Group Investigation Berbantuan Macromedia Flash terhadap Kemampuan Pemahaman Konsep Matematis. Seminar Nasional Matematika Dan Pendidikan Matematika (4th Senatik), 309-317.

Lestari, S. (2017). Penerapan Pembelajaran Group Investigation Untuk Meningkatkan Prestasi Dan Keaktifan Siswa Materi Statistika. Journal of Medives, 1(2), 150-157.

Mulyono, B., \& Hapizah, H. (2018). Pemahaman Konsep Dalam Pembelajaran Matematika. KALAMATIKA Jurnal Pendidikan Matematika, 3(2), 103-122.

Napratilora, M., Lisa, H., \& Bangsawan, I. (2020). Using WhatsApp as a Learning Media in Teaching Reading. MITRA PGMI: Jurnal Kependidikan MI, 6(2), 116-125. https://doi.org/10.46963/mpgmi.v6i2.129

Pradja, B. P., \& Baist, A. (2019). Analisis kualitatif penggunaan Microsoft Teams

319 BRILIANT: Jurnal Riset dan Konseptual Volume 6 Nomor 2, Mei 2021 
dalam pembelajaran kolaboratif daring. Seminar Nasional Matematika Dan Pendidikan Matematika (4th Senatik), 415-420.

Prasetyo, E., Susiswo, \& Hidayanto, E. (2019). Pembelajaran Kooperatif dengan Pendekatan SAVI untuk Meningkatkan Hasil Belajar Siswa Kelas X SMK Gajah Mada Banyuwangi. Jurnal Kajian Pembelajaran Matematika, 2(1), 10.

Retno, E. (2014). Pengembangan Model Pembelajaran Group Investigation ( GI ) Berbantuan Video Camtasia Pada Materi Peluang Untuk Siswa SMA / MA Negeri Kabpaten Cilacap. Jurnal Elektronika Pembelajaran Matematika, 2(5), 478-490.

Roestika, Z., Kartono, R., \& Hidayah, I. (2019). Conceptual Understanding of Class V Students Judging from Curiosity on Learning Models Group Investigation with Hands on Activity Assisted by Teaching Aids . 8(1), 229235.

Schumann Eriksson, V. (2020). Technology enabling project managers' knowledge sharing: the case of Microsoft Teams.

Sukoriyanto, S., Nusantara, T., Subanji, S., \& Chandra, T. D. (2016). Students' Errors in Solving the Permutation and Combination Problems Based on Problem Solving Steps of Polya. International Education Studies, 9(2), 11. https://doi.org/10.5539/ies.v9n2p11

Sumaji, Sa'Dijah, C., Susiswo, \& Sisworo. (2020). Mathematical communication process of junior high school students in solving problems based on APOS theory. Journal for the Education of Gifted Young Scientists, 8(1), 197-221. https://doi.org/10.17478/jegys.652055

Utami, F. D., Djatmika, E. T., \& Sa'dijah, C. (2017). Pengaruh Model Pembelajaran terhadap Pemahaman Konsep, Sikap Ilmiah, dan Kemampuan Pemecahan Masalah Matematis Ditinjau dari Motivasi Belajar Siswa Kelas IV. Jurnal Pendidikan: Teori, Penelitian Dan Pengembangan, 2(12), 16291638.

Wisra, A. (2019). Pengaruh Model Pembelajaran Kooperatif Tipe Group Investigation Terhadap Pemahaman Konsep Matematis. Jurnal Serunai Matematika, 11(1), 60-67.

Yemi, T. M., Azid, N. B. H., \& bin Md Ali, M. R. (2018). Cooperative Learning: an Approach for Teaching Mathematics in Public School. European Journal of Social Sciences Studies, 122-133.

Yuliani, E. N., Zulfah, \& Zulhendri. (2018). Kemampuan Pemahaman Konsep Matematis Peserta didik Kelas Viii Smpn 1 Kuok Melalui Model Pembelajaran Koopearatif Tipe Group Investigation. Jurnal Pendidikan Matematika, 2(2), 90-102.

Zahara, E., Murni, A., \& Hutapea, N. (2020). Development of Mathematics Learning Tools by Implementing Numbered Head Together Type Cooperative Models to Improve Students' Mathematical Understanding Ability in Matrix Topic. Journal of Educational Sciences, 4(4), 190-204.

Zengin, Y., \& Tatar, E. (2017). Integrating Dynamic Mathematics Software into Cooperative Learning Environments in Mathematics. International Forum of Educational Technology \& Society Integrating, 20(2), 74-88. 